\title{
Making it fit - strategies for harbouring public sector service design
}

\author{
Katarina Wetter-Edman \\ aÖrebro University Holding AB, Örebro University \\ University, Sweden*Corresponding author e-mail: katarina.wetter-edman@oru.se
}

\begin{abstract}
:
The benefit of service design for public sector actors surge for renewal is increasingly being discussed. Initiatives to integrate service design as method and practice are growing, however to what extent the new knowledge actually docks into the existing organisations are not known. Through an interview study this paper explores the ripples of two early initiatives to introduce service design in a Swedish region. Adaptation and repetition are found to be two diverse strategies for attempting to harbour service design in regional health care and municipalities respectively.
\end{abstract}

Keywords: Service design, design integration, design capability, public sector,

\section{Introduction}

The pressure on local and national governments to address increasingly complex issues in parallel with a population posing higher demands for better fit with their needs has opened up a search for alternative approaches to development of public service and policy. Design knowledge in form of service design (SD) has been suggested to be means to respond to these challenges (Bailey \& Lloyd 2017; van Buuren et al 2020). Research has focused design knowledge organized in labs and increasingly pinpoints the difficulties when design practice and knowledge meet public professional and management practices (Lewis 2020).

Another approach is to integrate design knowledge within the public organizations aiming to increase the capability for change. There are however difficulties in accepting knowledge from other fields when working with improvements in e.g. healthcare (Gadolin \& Andersson, 2017). Boström, Hillborg and Lilja (2020), also found tensions using design thinking and designerly support through a healthcare improvement project. In comparison with improvement knowledge, design knowledge is grounded in a quite different epistemological tradition. Based in the humanities and with strong artistic qualities, design forwards explorative, aesthetic, iterative and inductive approaches (Rylander 2009; Jones 2013).

The purpose of this paper is to explore what strategies have been employed for introducing and harboring SD long term in public sector organizations in one Swedish region. 


\section{A note on public sector renewal}

The search for alternative approaches to dominant management paradigm such as New Public Management has been ongoing for some time (Osborne 2018; Hartley 2005). Aligning with this is a need to increase the capability to change the public sector. To change from a paradigm of delivery of public services towards a service logic i.e., co-creation of public value (Osborne 2018). Hitherto, means to do so has been principles, methods and tools from improvement science and quality management to increase quality.

Quality literature has begun to question if too much focus has been on quantitative methods (Bergman et al, 2015). According to Cole and Matsumiya (2007, p. 91), quality routines are excellent for reducing faults and for working with continuous improvements. However public organizations oftentimes suffer from a "risk-averse culture" and are less suited to achieve radical solutions. Stephens and Boland (2015) bring forward that "organizational systems hoping to use designerly knowledge may need to engage in considerable reforms or adjustments." Suggesting that the main contribution of design is also the main barrier to its integration in organizational contexts.

\section{Establishing design capabilities in public sector}

Public sector innovation labs have become a means to address perceived shortcomings in local and national governments (Bailey \& Lloyd 2017; van Buuren et al 2020). Some employ design-driven processes in these ambitions (McGann et al 2018). Design competence is then often placed in a socalled lab and framed as a practice that forwards exploration and experimentation (Junginger 2018). Further design practice use of embodied and aesthetic knowledge is key contributions to public organizations (Stephens \& Boland 2015).

However, the sustainability and integration of this kind of organizations seem weak (Lewis 2020). Integrating service design knowledge within the organizations with the purpose to forward transformation on several levels might be an alternative approach since service inherently involves the organization ant it's employees (Sangiorgi 2011; Aguirre Ulloa 2020). Intentionally increasing the organizations design capability (Aricò 2018; Malmberg 2017), being the understanding of design as a resource. Design capability consists of the organizations knowledge of design, resources to design and how the organizational structures support design knowledge (Malmberg 2017).

With this integration a renewed discussion on expert versus diffused design knowledge has occurred (Manzini \& Coad 2015; Malmberg \& Wetter-Edman 2016). Specific difficulties when integrating design in the public sector concerns weak communities of practice, individuals learning processes and insufficient management structures (Holmlid \& Malmberg 2018).

\section{Empirical context and method}

The study has explored how SD has been introduced and established within the Swedish Region X. This research study is embedded in a longer research project with a duration from January 2017 through October 2021. 


\subsection{Empirical context}

Public actors in Region X had been pioneering in the use of SD in Sweden for public sector renewal and innovation. An indicator for this was that they had been taking part in two early national design projects, that has been pinpointed as the starting point for SD in the region:

- Change radically: 9 Swedish municipalities participated in a 10 month long design process. Initiated by The Swedish Association of Local Authorities and Regions (SALAR), coordinated and coached by a SD firm (Lindström et al 2015).

- Chronically Engaged: initiated by the Ministry of Social Affairs to explore the situation of patients with chronical diseases. It involved a primary care center in Region $\mathrm{X}$, and one in Region $\mathrm{Y}$, was coordinated by the National Design Lab (NDL), and the process was run by the same SD firm over 6 months.

\subsection{Method}

During 2017-2019 the author was part of, and initiated SD driven projects, action research initiatives and educational efforts in the region. When arriving the Region was about to enter into collaboration with the NDL, however never established a regional lab but employed designers as developers and engaged in diverse set of educational efforts.

An interview study was conducted December 2019- January 2020 with purpose to trace the development of SD. The respondents for this study was key persons for the introduction of SD in the region. In all 10 people was interviewed, the format was a loosely structured, open-ended interview format all but one was conducted by the author. For distribution of respondents see Table 1.

The interviews focused on the individuals proper experience of SD, lasted 42-55 minutes and was transcribed by an external person. Interviews were analysed using Interpretative Phenomenological Analysis (IPA) (Smith, Flowers \& Larking 2012). The format of this paper doesn't allow for an extended empirical representation, quotes are used to exemplify and connect with the empirical material.

\begin{tabular}{|l|l|l|l}
\hline $\begin{array}{c}\text { Respondent } \\
\text { ID }\end{array}$ & $\begin{array}{c}\text { First introduced to } \\
\text { SD }\end{array}$ & \multicolumn{1}{|c}{ Employer } & \multicolumn{1}{c}{ Profession/role } \\
\hline R1 & 2014 & Muncipality 1 & Controler/manager \\
\hline R2 & 2013 & Region Primary Care & Registered Nurse/manager \\
\hline R3 & 2013 & Region Primary Care & Registered Nurse/developer \\
\hline R4 & 2015 & Municipality 2/Region & Service/manager \\
\hline R5 & 2015 & Muncipality 2/region staff & Regional development/developer \\
\hline R6 & 2016 & Municipality 2 & Teacher/Innovation strategist/Developer \\
\hline R7 & 2014 & Region Care Development unit & Registered Nurse/Development manager \\
\hline R8 & 2014 & Region Sustainable development & Divsion manager/former county council director \\
\hline R9 & 2012 & Region Care development unit & Registered nurse/development manager/PCC \\
\hline R10 & 2014 & Muncipality 2 & Change leader/Manager \\
\hline
\end{tabular}

\section{Ripples from key interventions}

Both of the two identified key projects took place in 2014, involving Municipality 2, and a County council primary care unit. As such 2014 could be seen as a basepoint for the introduction of SD in 
both contexts. In Appendix 1 a selection of events and the respondents' relations to these are mapped.

\subsection{Change radically, Municipalities}

This project is repeatedly mentioned as the starting point for the three respondents from the municipalities. None of them mention that they had heard of or been in touch with SD prior to the 2014 project. This encounter is described with excitement, it was something new, and the experience of participating really altered their way of perceiving their own mission. R10 was then a middle manager in Municipality 2 receiving support and mandate from top and political management to take part in the first national project. The following year, R10 and R5 repeated, still with top management support, the same procedure with other administrative units of the municipality. They now led and coached the teams with employees on their own, based on the experience gained from participating in the first round. The design process was run over 10 months, using the same format and templates as the national version. In 2016, the process was repeated, inviting other municipalities in the region and R1 participated. R1 has since implemented the outcome, but still struggle to integrate SD in the municipality. Using the same format, the process was repeated a third time in 2017 now also inviting regional health and care units. See fig 1 for timeline and content of projects. R10 has been managing both the process and involvement of colleagues for coaching. Over the years, she states, 30-40 teams have participated in these processes, and several implemented outcomes.

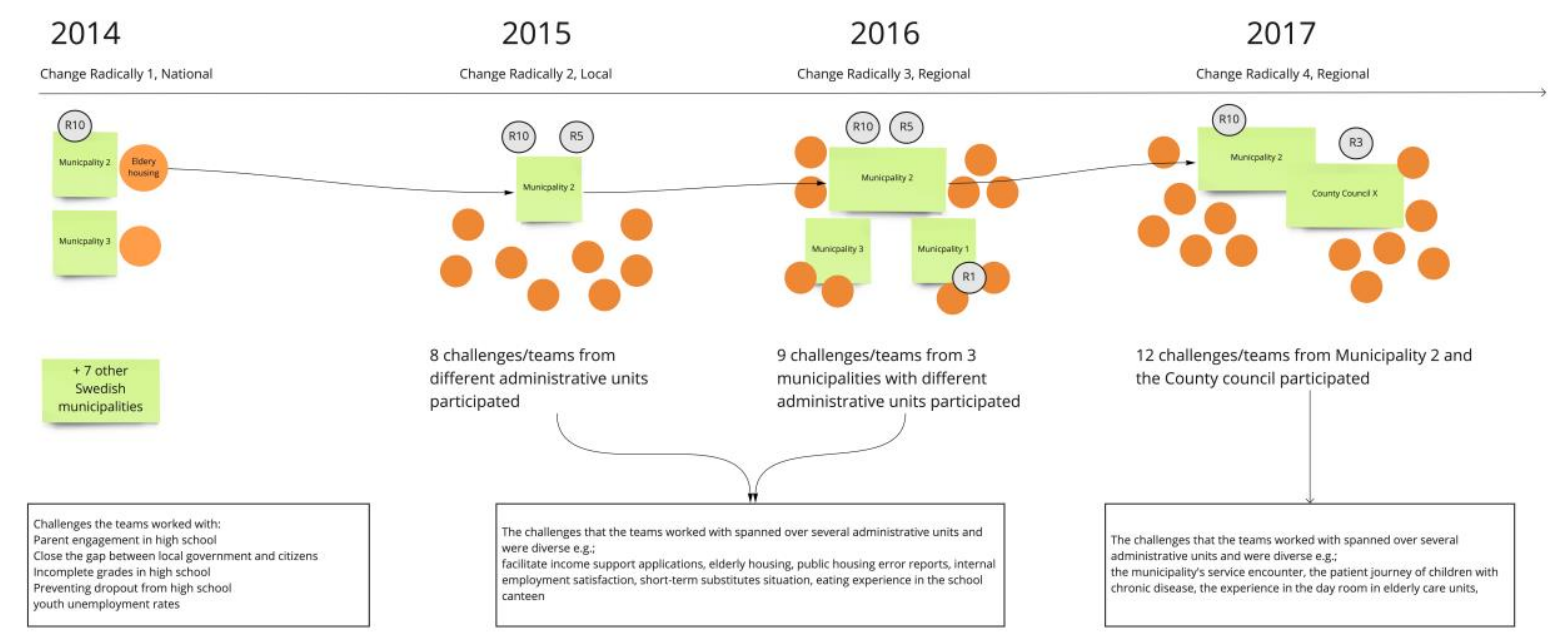

Figure 2 Timeline of SD development from Change Radically

\subsection{Chronically engaged, Regional Primary care}

Although this project is mentioned by all the respondents from the Region, and was important in the understanding of SD, this was not the starting point it seemed like. Instead, a policy decision to implement person centered care (PCC) did catalyze the introduction of SD in 2012. Another SALAR project "Care on equal terms", was the starting point for R2, truly incorporating the patient's perspectives. In 2012, R9 was employed to coordinate the implementation of PCC, and introduced SD as means to reach this goal through a pilot project for PCC, where the NLD was invited at a seminar. Only in 2014 Chronically Engaged was set up by R9 and R3 together with the professional SD firm 
conducting the design work. The project resulted in a set of prototypes. In 2016, Chronically Engaged 2.0 was carried through led by R3 and a consultant service designer, with one of the prior and three new primary care centers, with the purpose to further develop and implement the prototypes from the first round, see fig 2 . In parallel, different educational initiatives have been developed with support of SALAR, and then adapted to fit the health care organization. According to R7 over 50 employees have passed through these short SD introductions. A wide range of other projects supported by SD have been carried out since, both with internal and external design support.

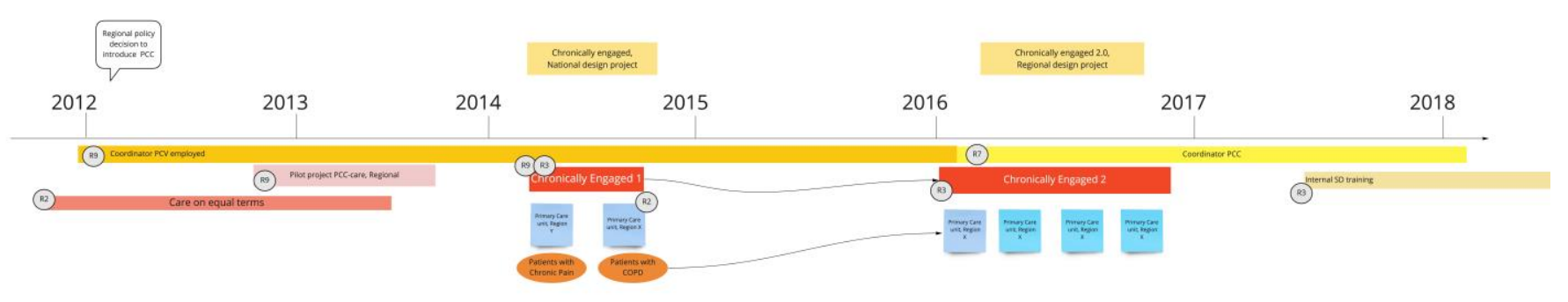

Figure 3 Timeline for SD development from Chronically Engaged

\section{Strategies for introducing and harboring SD}

The search for novel ways of working supporting a transition of the public organizations has been a mutual driver for both the regional and municipal context to introduce SD. However, the strategies for introducing and harboring the knowledge of SD long term differed, as the results thereof. The municipalities used a strategy of repetition, applying a similar SD-format with new actors. By connecting SD to a strategic policy decision, the region continuously worked with a strategy of adaption, working to some extent with the same actors to achieve a better fit.

\subsection{Repetition}

"I believe in this, and for me it has meant a perspective shift and I have fought to get more people to experience this. That is why I have tried to spread this work since then." (R10 Municipality)

Although supported by top management, R10, the person that brought SD to the municipality has taken it as a personal task to spread it further. Through conducting in all 4 consecutive rounds, she has involved a vast amount of people and organizations working on diverse set of concerns while getting introduced to SD methods. The process has been minimally altered to fit their purposes. Supported by colleagues that has taken on coaching roles the format has been spread and is described as satisfactory and fun to work with.

The strategy was to work with internal competence, and training through participation, as such the process has been led by laymen design competence. SD is described foremost as a method, but also at times as approach. R5 mentioned that one reason to open up for other actors in the third round was the lack of teams and challenges to work with from their own administrations. Similar can be seen in the case of Municipality 1, that had a very successful outcome from their participation and R1 has implemented and continued to coordinate the result. The management wants to introduce the methods and she has the role to work with SD in the municipality but find it difficult. 
"Yes, I have a small team, we have been trained, we have met the managers ... the only problem is that we do not get anything to start working with." (R1 Municipality)

The respondents return to the economic dimensions, the importance of efficiency, and the difficulty to work across administrative functions. How SD doesn't fit within the existing framework.

"The internal perspective still prevails. We have not made the change of perspective as organization, it is individuals who have participated who have done it, but it is still a fight to get the recipe. Even so, it may not be openly questioned, but at the same time it is this perspective you bring into a new project or new task." (R10 Municipality)

Six years after the first project SD as not been integrated at a structural level in either of the two municipalities.

\subsection{Adaptation}

"It goes as I said, hand in hand, service design and to implement or concretize a person-centered approach, person-centered culture that is what we try to achieve." (R2 Regional Health and Care)

"I am very grateful that we didn't put this into a specific project, but that we chose to rub it into our regular business" R7, Regional Health and Care

As with the municipalities SD was introduced by an individual but was immediately connected to the strategic agenda of PCC. The Chronically Engaged project was led by a design firm that conducted the main part of the actual design work. In the second edition, a designer was employed to support the development of the format to fit the needs of the situation, as in the development of the PCC based primary care unit. There have additionally been different forms of SD-training programs, both developed by design firms, and the train-the-trainer concepts from SALAR. The learnings from these have then been further developed to an internal training program.

One of the obvious adaptions is a change of labelling, instead of SD, the methods and approaches are promoted as "needs-oriented organizational development". To fit with the organizational language and the one of PCC. There is also a concern about fit, not only with the organization but with the employees' personal strategies.

\footnotetext{
"As a staff, you must have a way of working where it fits. What I experience more and more is that healthcare professionals want to be very nice to their patients and they want to care as well as possible for everyone. So they have found different strategies in this complex system to deal with it, to make it as good as possible. Many have worked, I think quite hard, to find functioning ways of working themselves, and then we introduce something that we think should be a solution to a problem from the side. It does not fit into these strategies that you yourself have worked out and then you see no point in using them. " (R3 Regional Health and care).
} 
The way R7, having the coordinating role for PCC, when R9 left for another position, has dealt with the integration of SD in the development unit work may be seen as one example of this. R7 is clear about that she sees SD as an add on, something that clearly complements what they are already doing, but it should not be seen as something strange or extra.

"I have consistently shown that this isn't strange. I get involved with people who, for example, have written decision documents. To get it in there from the start." R7 Regional Health and Care

For her it is less important what it's called, the most important is to get the users perspectives and needs integrated in the development processes as well as in the outcomes thereof.

Even though there are extensive efforts made to adapt SD methods there are still concerns. The economic aspect is present, but less so in the municipality context. Again it is the fit, that is the concern.

\footnotetext{
"No, but the biggest resistance is that it does not fit in our ... We plan to do this and then we will come to this outcome and then you can measure on this and then we know what we get. [...] But you never know where we end up and then also that it is ... yes you can say agile or iterative [...] It is not linear, and much more uncertain and there is a resistance to it because you do not know what you say yes to if you want to push through a project where you work with these methods. You can end up somewhere else." (R3, Region Health and Care)
}

The uncertainty of the result and the reluctancy of SD and its outcomes to fit the organizational constraints is still an issue despite the time spent on education and adjustments.

\section{Lost in adaptation or repetition}

The analysis has shown that the strategies for introducing and establishing SD in these two public contexts differed.

For the municipalities the logic seems to be: If enough people have experienced this, then it should work. And to some extent it does, there are implemented services, there are a higher number of personnel that are aware, but the systemic shift does not take place. The reliance on individual learning and lacking supporting structures has hampered the integration in line with Holmlid and Malmbergs findings (2018). There are really no traces that it even has started more than on the individual level. It might even be so that the SD processes used is too different to successfully penetrate the structure more than in small fragments. Led by experienced but laymen design coaches, the knowledge for thoughtful adaptations might be lacking.

In contrary, the regional adaptation seems to work in terms of getting the work done. If the work is to infuse the organizations with an increased user focus. In this context professional designers have been involved to shape some of the projects and their outcomes. The respondents that worked with them are convinced that their professional competence was key to their success. The SD initiatives have also been docked to existing development knowledge. However, the further the integration goes into the regular development process there might be a development of a hybrid community of 
practice, and will then the core of design knowledge sustain? Is that even important if the purpose of the integration is to achieve PCC?

\section{Conclusion}

That SD doesn't fit is a reoccurring experience both from the Municipalities and the County councils health care actors. The strategies on how to address this is completely different. The municipality case goes about this challenge by doing more of the same, while the regional strategy has been to make adaptation of SD.

Finally, the question of measurement is still dominant, and design's reluctancy or even inability to fit in an excel sheet is key. Still people get engaged to the extent to change their careers and spend their work life on spreading SD. Because service design taps into the knowledge domain that to large part is lacking within our public organizations.

\section{References}

Aricò, M. (2018). Service Design as a Transformative Force: Introduction and Adoption in an Organizational Context. Frederiksberg: Copenhagen Business School (CBS).

Bailey, J., \& Lloyd, P. (2017). The introduction of design to policymaking: policy lab and the UK government. Annual Reviw of Policy Design, (5(1), 1-14.

Bergman, B., Hellström, A., Lifvergren, S. \& Gustavsson, S. (2015). An Emerging Science of Improvement in Health Care. Quality Engineering, 27(1), p. 17-34.

Boström, J., Hillborg, H. \& Lilja, j. (2020). Cultural dynamics and tensions when applying design thinking for improving health-care quality. International Journal of Quality and Service Sciences, 13(1).DOI 10.1108/IJQSS-04-2019-0055

Cole, R.E., \& Matsumiya, T. (2007). Too much of a good thing? Quality as an impediment to innovation. California Management Review, Fall, 50(1), 77-93.

Hartley, J. (2005). Innovation in governance and public services: Past and present. Public money and management, 25(1), 27-34.

Holmlid, S., \& Malmberg, L. (2018, July). Learning to design in public sector organisations: A critique towards effectiveness of design integration. In ServDes2018. Service Design Proof of Concept, Proceedings of the ServDes. 2018 Conference, 18-20 June, Milano, Italy (No. 150, pp. 37-48). Linköping University Electronic Press.

Gadolin, C., \& Andersson, T. (2017). Healthcare quality improvement work: a professional employee perspective. International Journal of Health Care Quality Assurance.

Jones, P. (2013). Design for Care - Innovating Healthcare Experiences. New York: Rosenfeld Media.

Junginger, S. (2018). Inquiring, Inventing and Integrating: Applying Human-Centered Design to the Challenges of Future Government. JeDEM-eJournal of eDemocracy and Open Government, 10(2), 23-32

Lewis, J. M. (2020). The limits of policy labs: characteristics, opportunities and constraints. Policy Design and Practice, 1-10. 
Malmberg, L. (2017). Building Design Capability in the Public Sector: Expanding the Horizons of Development, Vol. 1831. Linköping: Linköping University Electronic Press. https://doi.org/10.3384/diss.diva-134167

Malmberg, L., \& Wetter-Edman, K. (2016). Design in public sector: Exploring antecedents of sustained design capability. In 20th DMI: Academic Design Management Conference-Inflection Point: Design Research Meets Design Practice, Boston, USA, July 22-29, 2016 (pp. 1287-1307). Design Management Institute.

Manzini, E., \& Coad, R. (2015) Design, When Everybody Designs : An Introduction to Design for Social Innovation. Cambridge, Mass.: The MIT Press.

McGann, M., Blomkamp, E., \& Lewis, J. M. (2018). The rise of public sector innovation labs: experiments in design thinking for policy. Policy Sciences, 1-19.

Rylander, A. (2009). Design thinking as knowledge work: Epistemological foundations and practical implications. Design Management Journal, 4(1), 7-19.

van Buuren, A., Lewis, J. M., Guy Peters, B., \& Voorberg, W. (2020). Improving public policy and administration: exploring the potential of design. Policy \& Politics, 48(1), p. 3-19.

Osborne, S. P. (2018). From public service-dominant logic to public service logic: are public service organizations capable of co-production and value co-creation. Public Management Review, 20(2), p. $225-231$

Sangiorgi, D. (2011). Transformative services and transformation design. International Journal of Design, 5(2), 29-40.

Stephens, J. P., \& Boland, B. J. (2015). The aesthetic knowledge problem of problem-solving with design thinking. Journal of Management Inquiry, 24(3), p. 219-232.

Author Bios:

Katarina Wetter-Edman is a designer and researcher at Social Impact Lab, Örebro University Holding and is Associate professor in Design at Linköping university. She has previously worked and conducted research with among others, the Government Offices of Sweden, Experio Lab Sweden, and Konstfack University of Arts, Crafts, and Design

Acknowledgements: This research has been funded by Riksbankens Jubileumsfond project No. RMP16-1159. The author is grateful to the participants of the interview study that freely and generously shared their experiences. 


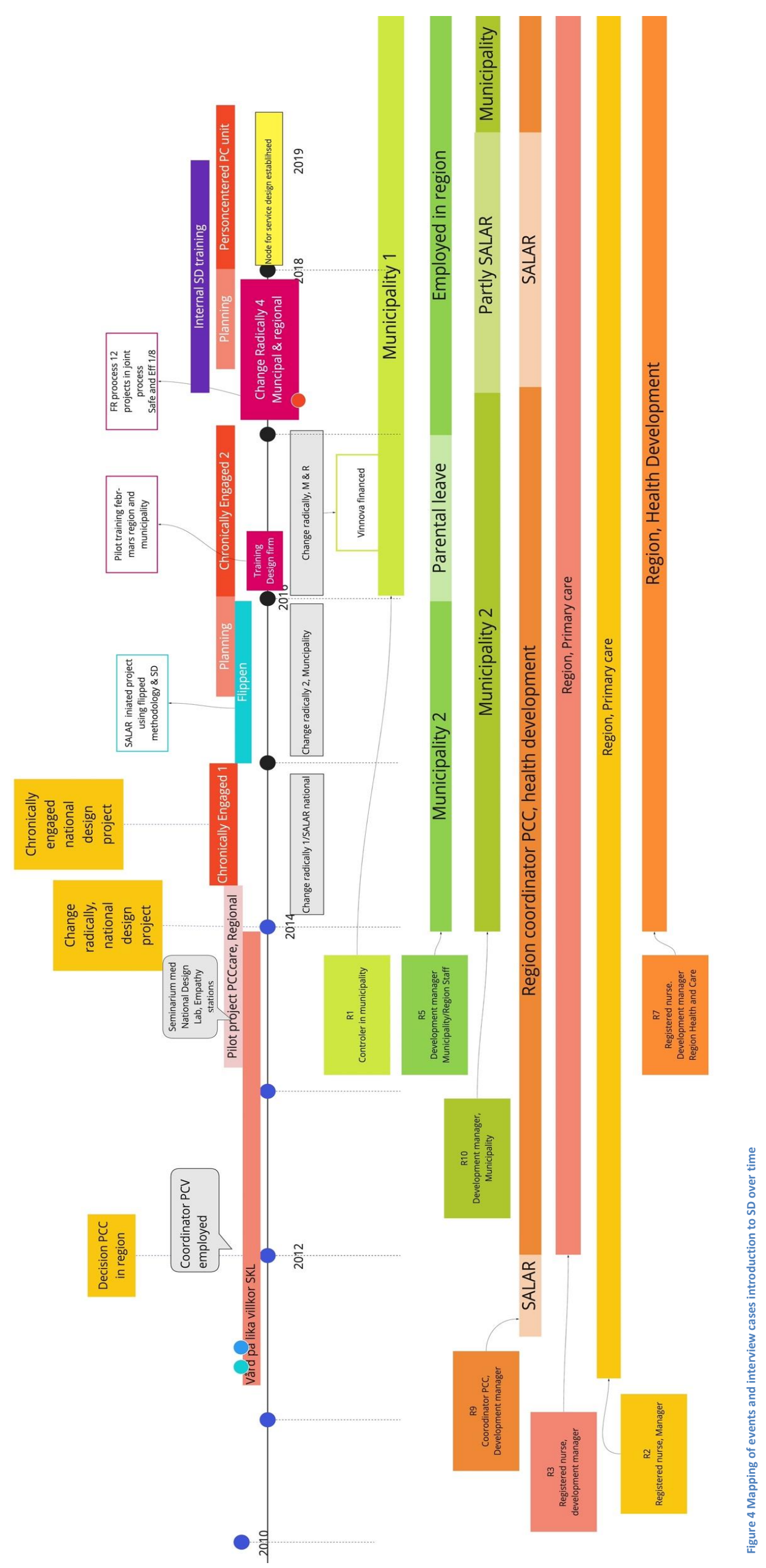

